\title{
Erratum to: A new species and a revised record in Namibian Barleria (Acanthaceae)
}

\author{
lain Darbyshire ${ }^{1}$, Erin A. Tripp ${ }^{2,3}$ \& Kyle G. Dexter ${ }^{4}$
}

Summary. Due to a production error, an out-of-date (uncorrected) pdf of this paper was uploaded onto Springerlink, and used for the print version of Kew Bulletin 67 (4): 759 - 766 (10.1007/s12225-012-9393-1). Consequently the authority abbreviation for the second author was incorrect. The new species name is published again below with the correct authority.

Barleria grootbergensis I. Darbysh. $\mathcal{E}$ E. Tripp sp. nov. resembling $B$. lancifolia $\mathrm{T}$. Anderson but differing in the more congested, spiciform yellow-green inflorescences with the calyces largely hidden within the suberect bracts during anthesis; the longer bracteoles and the longer glandular inflorescence indumentum that is more dense on the bracts. Type: Namibia, W of Grootberg Pass, Tripp E $\mathcal{F}^{2}$ Dexter 828 (holotype RSA!; isotypes $\mathrm{K}$ !, NY!, WIND!).

http://www.ipni.org/urn:lsid:ipni.org:names:77120498-1

The online version of the original article can be found at http://dx.doi.org/10.1007/s12225-012-9393-1

Published online 26 March 2013

1 Herbarium, Royal Botanic Gardens, Kew, Richmond, Surrey, TW9 3AB, UK. e-mail: i.darbyshire@kew.org

2 Rancho Santa Ana Botanic Garden, 1500 N. College Ave., Claremont, CA 91711, USA.

3 Present address: University of Colorado, Boulder, Museum of Natural History, COLO Herbarium, 350 UCB, Clare Small Building, Boulder, CO 80309-0350, USA. e-mail: erin.tripp@colorado.edu.

${ }^{4}$ Royal Botanic Garden Edinburgh, 20a Inverleith Row, Edinburgh, EH3 5LR, UK. 